\title{
Effect of the structure of ethylene-propylene-diene-graft- polystyrene graft copolymers on morphology and mechanical properties of SAN/EPDM blends
}

\author{
A. Ptiček, Z. Hrnjak-Murgic', J. Jelenčic \\ Faculty of Chemical Engineering and Technology, University of Zagreb, P.O. Box 177, 10000 Zagreb, Croatia
}

Received 25 January 2007; accepted in revised form 6 March 2007

\begin{abstract}
Ethylene-propylene-diene-graft-polystyrene (EPDM-g-PS) copolymers were synthesized to obtain different structures of graft copolymers with different graft lengths and graft densities. The structure of synthesized EPDM-g-PS copolymers was characterized by gel permeation chromatography (GPC) and by Fourier transforms infrared spectroscopy (FTIR). These presynthesized graft copolymers were added (5 phr) to styrene-acrylonitrile (SAN) and ethylene-propylenediene (EPDM) blends, prepared to maintain the following SAN/EPDM ratios a) 95/5 and b) 90/10. SAN/EPDM blends were characterized by the determination of mechanical properties (tensile strength, elongation at break) while their morphology was inspected by scanning electronic microscopy, SEM. The obtained results show that various structures of EPDM-g-PS copolymers influence the miscibility in SAN/EPDM blends. Optimal concentration of side branches of graft copolymers provide the finest morphology and enhance mechanical properties.
\end{abstract}

Keywords: mechanical properties, graft copolymer, styrene-acrylonitrile, ethylene-propylene-diene monomer, morphology

\section{Introduction}

Combining two polymers by blending is one of the most favourite techniques used to generate new polymeric materials, as confirmed by the available literature on polymer blends abounding in data on immiscible systems [1-5]. Most incompatible polymer blends often manifest high interfacial tension and weak adhesion at the interfaces between the dispersed phase and the matrix. That results in inferior mechanical properties as well as coarse and unstable morphology. Compatibility of such blends can be enhanced by the addition of an appropriate presynthesized block or graft copolymers $[6,7]$ with different segments, having affinity for either of the two blend components.

Graft copolymers have a wide range of application owing to the possibility of tailoring their properties trough a combination of monomers that form the backbone and side chains. One can thus obtain thermoplastic elastomers by combining a soft polymer backbone with hard polymer grafts, or vice-versa [8]. The obtained structure of graft copolymers with several branches significantly differs from the linear structure due to its high segment density which considerably affects the crystallization process, as well as, the final mechanical and viscoelastic properties. The addition of a small amount of graft copolymer to an immiscible polymer blend is often a powerful means to increase interaction between the phases, and thus enhance the mechanical properties due to the formation of a strong interface. The graft copolymer used as a compatibilizer tends to be located at the interface of two components and improves adhesion by the 'bridge' effects of the chains $[9,10]$. 
In order to obtain different structures of graft copolymers (graft densities), the use of various types of coagents has become popular in many investigations [11]. Thus, the participation of a small amount of coagent (triallylcyanurate, TAC) will suppress the grafting reaction at the tertiary $\mathrm{C}$ atom of the main chain of the EPDM polymer, which leads to a diminished grafting efficiency [12]. The diversity of possible structures along with the adequate selection of the main backbone facilitates the process of tailoring of the properties of graft copolymers. Grafting reactions could induce significant changes in the polymer chain like the chemical composition, the polymer chain structure, the size of molecular masses and these parameters are responsible for the interactions between polymers.

The aim of this work was to investigate the effect of various structures of presynthesized EPDM-g-PS copolymers on interactions between SAN and EPDM polymers in blends. The effect of dissimilar graft copolymers structures on compatibility in blends was followed by the examination of morphology and the determination of mechanical properties.

\section{Experimental}

\subsection{Materials}

Polymers used for the synthesis of graft copolymers were ethylene-propylene-diene (EPDM, Keltan 312, DSM) containing $55 \mathrm{wt} \%$ ethylene and $4 \mathrm{wt} \%$ ethylidene norbornene, Mooney viscosity $36 \mathrm{MU}$, monomer styrene (St) $99.8 \mathrm{wt} \%$ was supplied by DIOKI (Croatia), and the triallylcyanurate (TAC; purity: $50 \mathrm{wt} \%$ ) which was used as coagent, was purchased to Bayer. Polymers used for the preparation of studied blends, were the above described EPDM and styrene-acrylonitrile (SAN, Tyril 790, The Dow Chemical Company) with $24 \mathrm{wt} \%$ AN, the melt flow rate (MFR, measured at $220^{\circ} \mathrm{C}$, using a load of $10 \mathrm{~kg}$ ) was $22 \mathrm{~g} / 10 \mathrm{~min}$.

\subsection{Preparation of samples}

Graft copolymers were prepared by in-situ polymerization by adding monomer styrene $\left(45.97 \mathrm{~cm}^{3}\right)$ to a toluene solution of the EPDM polymer $(10 \mathrm{~g})$. Dibenzoyl-peroxide $(0.39 \mathrm{~g})$ was used as an initiator and the reaction was carried out at $90^{\circ} \mathrm{C}$. One series of graft copolymers was synthesized for various polymerization times ( 3 and 7 hours) while the second series was synthesized with the addition of coagent TAC (1.5 phr) in order to design different structures of graft copolymers. After the synthesis, EPDM-g-PS copolymers were separated from the polymerization solution by Soxhlet extraction in tetrahydrofurane for 8 hours [13]. Extracted graft copolymers were further used as compatibilizer (5 phr) in SAN/EPDM blend compositions 95/5 and 90/10. Studied blends were prepared as thin films $(1 \mathrm{~mm})$ cast from $6 \mathrm{wt} \%$ toluene solution; their compositions are listed in Table 1. The grafting efficiency was determined on the basis of polymer weight and the total amount of EPDM-g-PS formed, respectively (Equation 1).

$$
\begin{aligned}
& \text { grafting efficiency }[\%]= \\
& \frac{\text { weight of EPDM - g - PS }}{\text { total weight of polymers formed }} \cdot 100
\end{aligned}
$$

\section{Characterization}

\subsection{GPC measurements}

The molecular masses $\left(\overline{M_{m}}, \overline{M_{w}}\right)$ of extracted graft copolymers were determined by gel permeation chromatography (GPC) (Polymer Laboratories, PL-GPC 20) using dilute polymer solutions ( $c=$ $10 \mathrm{mg} / 5 \mathrm{ml}$ ) in THF at room temperature at a rate of $1 \mathrm{ml} / \mathrm{min}$.

\subsection{FTIR spectroscopy}

FTIR spectra were recorded on a Perkin-Elmer Spectrum One, in the range of $4000-500 \mathrm{~cm}^{-1}$, with

\begin{tabular}{|c|c|c|c|c|c|c|c|c|c|c|}
\hline Samples & & & & SAI & -1-3* & & & SAI & & \\
\hline SAN & 95 & 90 & 95 & 95 & 90 & 90 & 95 & 95 & 90 & 90 \\
\hline EPDM & 5 & 10 & 5 & 5 & 10 & 10 & 5 & 5 & 10 & 10 \\
\hline EPDM-g-PS & - & - & 5 & - & 5 & - & 5 & - & 5 & - \\
\hline EPDM-g-PS + TAC & - & - & - & 5 & - & 5 & - & 5 & - & 5 \\
\hline
\end{tabular}

Table 1. Composition of SAN/EPDM/EPDM-g-PS blends

*samples prepared with EPDM-g-PS copolymers synthesized for 3 and 7 hours 
resolution of $4 \mathrm{~cm}^{-1}$. Samples were prepared as thin films cast from $6 \%$ toluene solution. The absorbance of vibrations at 1453 and $1493 \mathrm{~cm}^{-1}$ due to the polystyrene aromatic groups in the graft copolymer was followed. The absorbance of $\left(-\mathrm{CH}_{2}-\right)$ rocking vibrations of the EPDM main chain at $722 \mathrm{~cm}^{-1}$ was used as an external standard to eliminate the differences in thickness of the recorded samples.

\subsection{Mechanical properties}

The mechanical properties of blends were tested using a Zwick Testing Machine (model 1445) at a constant temperature of $23^{\circ} \mathrm{C}$ and the humidity of $70 \% \mathrm{RH}$. The gauge length of $45 \mathrm{~mm}$, crosshead speed of $1 \mathrm{~mm} / \mathrm{min}$ and sample size $(75 \times 13 \times 1 \mathrm{~mm})$ were used to determine of tensile strength and elongation at break. The results are the average of five samples.

\subsection{Scanning Electron Microscopy (SEM)}

Morphology of examined blends was characterized by a cross-section of cryogenically fractured surfaces of film samples ( $1 \mathrm{~mm}$ thick) using a Philips XL 30 Scanning Electron Microscope. The samples were immersed in liquid nitrogen to cool down for more than $15 \mathrm{~min}$, and then fractured immediately. The dried samples were sputter-coated with gold prior to scanning electron microscopy (SEM) examination.

\section{Results and discussion}

\subsection{Characterization of presynthesized EPDM-g-PS copolymers}

The grafting mechanism proceeds with the formation of radical centers in the EPDM chain by break-
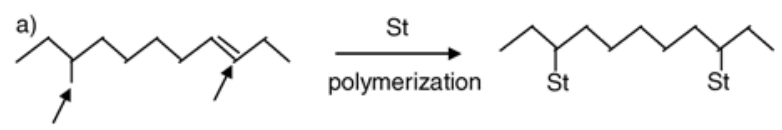

b)



c)

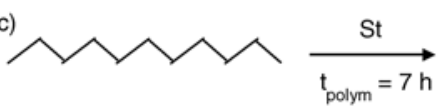

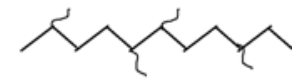

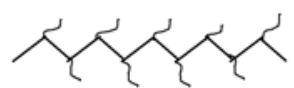

Figure 1. a) possible grafting locations, b) graft density of side branches after 3 hours, c) graft density of side branches after 7 hours

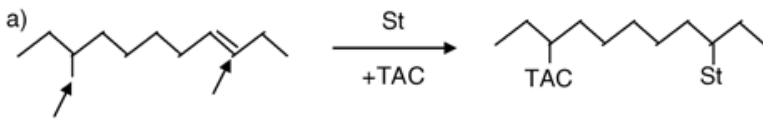

b)

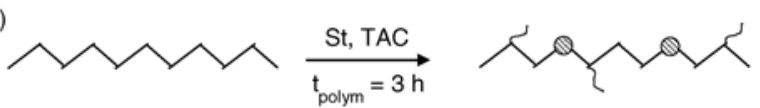

c)

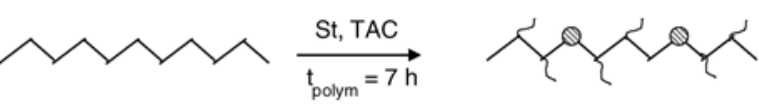

Figure 2. a) suppresion of grafting, b) graft density of side branches after 3 hours, c) graft density of side branches after 7 hours ( 8 - active centers blocked by $\mathrm{TAC}$ )

ing the double bond in the third monomer (ENB in EPDM) and in the tertiary C-atom by the abstraction of secondary hydrogen, Figure 1a. At these two active centers of the backbone it is possible to create a modified structure of graft copolymers by: a) extending the polymerization time, and b) adding the coagent TAC. It is expected that with the extended polymerization time the number of side branches would increase, Figures 1b, 1c, whereas in the presence of the coagent TAC the number of side branches would decrease Figures $2 b, 2 c$. The results of grafting efficiency and the molecular masses of synthesized graft copolymers confirmed this assumption, Table 2 . The grafting efficiency increase is due to an increasing number of grafting points along the backbone of EPDM. For example, the grafting efficiency at 3 hours of polymerization was $35.6 \%$ and at 7 hours $58.5 \%$.

The results of determined molecular masses of synthesized EPDM-g-PS copolymers, Table 2, show that the values increased due to a continuous decomposition of the initiator during the reaction time. A significant increase in the values of molecular masses $\left(\overline{M_{n}}=26200\right.$ of the EPDM-g-PS-3 and $\overline{M_{w}}=54000$ of the EPDM-g-PS-7) was obtained because during the polymerization side branches

Table 2. Characterization of synthesized EPDM-g-PS copolymers

\begin{tabular}{|l|c|c|c|}
\hline \multicolumn{1}{|c|}{ Samples } & $\begin{array}{c}\text { Grafting efficiency } \\
{[\boldsymbol{\%}]}\end{array}$ & $\overline{\mathbf{M}}_{\mathbf{n}}$ & $\overline{\mathbf{M}}_{\mathbf{w}}$ \\
\hline EPDM virgin & - & 95000 & 313000 \\
\hline EPDM-g-PS-3 $^{\mathrm{a}}$ & 35.6 & 15900 & 26200 \\
\hline EPDM-g-PS-7 $^{\mathrm{a}}$ & 58.5 & 35000 & 54000 \\
\hline EPDM-g-PS-3-T $^{\mathrm{b}}$ & 31.9 & 14800 & 25800 \\
\hline EPDM-g-PS-7-T $^{\mathrm{b}}$ & 43.8 & 20000 & 42000 \\
\hline
\end{tabular}

agraft copolymers synthesized without TAC

bgraft copolymers synthesized with TAC 
continuously are formed and an increase in the free molecular volume of the graft copolymer was present. The increase in weight molecular mass, $\overline{M_{w}}$, implies a higher graft density, i.e. higher concentration of side branches [14] and that is the result of a higher degree of branching and a higher number of conformations.

The influence of coagent TAC on graft composition can be seen from the results of the grafting efficiency. Significant decrease in grafting efficiency was observed for the graft copolymers synthesized without coagent TAC (58.5\% for $7 \mathrm{~h}$ of polymerization) in comparison with graft copolymers synthesized with coagent $(43.8 \%$ for $7 \mathrm{~h}$ of polymerization). These results are explained by 'blocking' the active centers (tertiary C-atom) on the EPDM chain by the coagent TAC, because the rate of reaction of TAC with backbone is faster than the rate of grafting, Figure 2a [15]. The result is a lower graft density of synthesized graft copolymers, as shown by the results relating to the grafting efficiency. Various conditions of graft polymerization lead to the creation of a different structure of graft copolymers, which is also supported by the results of the FTIR characterization.

The grafting reaction of polystyrene on the main EPDM chain was studied via aromatic groups which caused the absorbance of vibrations at 1453 and $1493 \mathrm{~cm}^{-1}$, Figure 3 . The higher concentration of polystyrene branches present in graft copolymers resulting as higher values of absorbance, which were calculated from the FTIR spectra. The values of absorbance in the EPDM-g-PS-7 copolymer were $A_{1453}=1.01$ and $A_{1493}=0.55$, while in

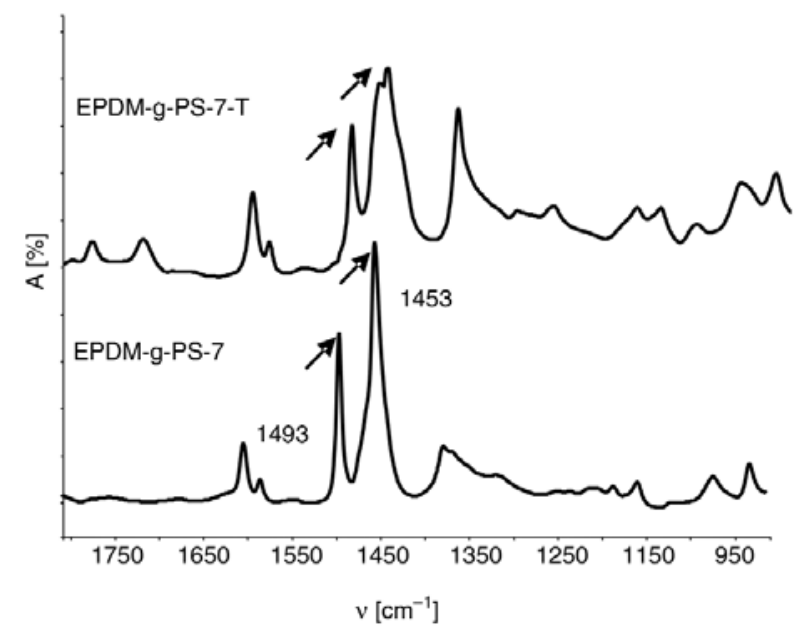

Figure 3. FTIR spectra of graft copolymers synthesized for 7 hours (EPDM-g-PS-7) and for 7 hours with the coagent TAC (EPDM-g-PS-7-T) the EPDM-g-PS-7-T they were $A_{1453}=0.86$ and $A_{1493}=0.48$, respectively. An addition of the coagent TAC prevents bonding of polystyrene groups onto EPDM chain, resulting in lower values of absorbance and these results also indicate certain differences in the grafting density.

\subsection{Mechanical properties of the SAN/EPDM/EPDM-g-PS blends}

The mechanical properties, tensile strength and elongation, of SAN/EPDM blends obtained by presynthesized EPDM-g-PS copolymers are given in Figures 4 and 5. The standard deviation of the measured results of mechanical properties was in the range $\pm(0.1-0.7)$. The first series of blends, denoted as SAN/EPDM-3, SAN/EPDM-7, were prepared by adding of graft copolymers synthesized for 3 and 7 hours. Samples denoted as SAN/EPDM-3-T, SAN/EPDM-7-T were prepared by adding graft copolymers synthesized in the presence of the coagent TAC as the second series, Table 1.

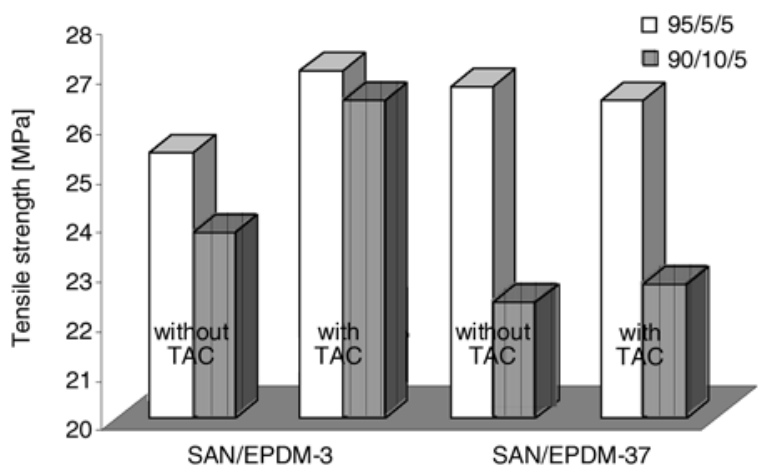

Figure 4. Tensile strength of SAN/EPDM-3, SAN/EPDM7, SAN/EPDM-3-T and SAN/EPDM-7-T blends compositions $95 / 5 / 5$ and $90 / 10 / 5$

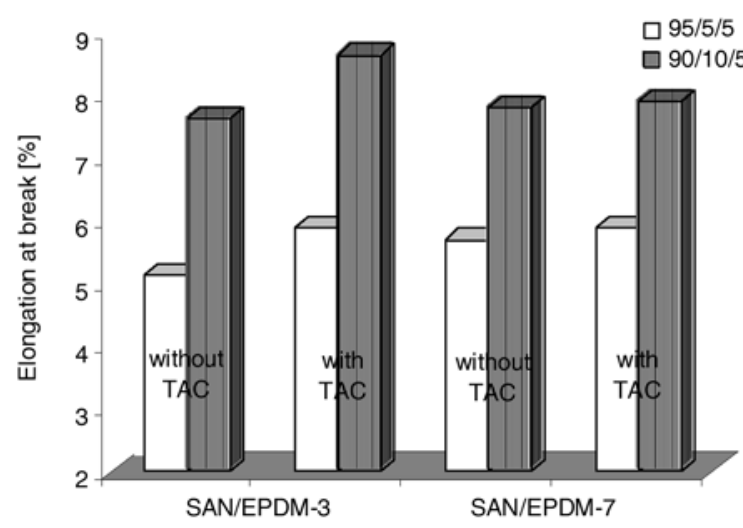

Figure 5. Elongation of SAN/EPDM-3, SAN/EPDM-7, SAN/EPDM-3-T and SAN/EPDM-7-T blends compositions $95 / 5 / 5$ and $90 / 10 / 5$ 
It is a well known fact [16] that SAN and EPDM polymers are incompatible due to the dissimilarity of chemical structure which exhibits poor mechanical properties of blends. Mechanical properties can be improved by adding an interfacial agent to enhance adhesion due to better interaction between the phases. The effect of compatibilizers on mechanical properties is well seen in blend compositions $90 / 10$ because various structures of presynthesized graft copolymers show different influence on the compatibility in SAN/EPDM blends. Optimal mechanical properties are obtained for sample SAN/EPDM-3-T (90/10/5) prepared by a compatibilizer synthesized with the coagent TAC, which implies a lower concentration of side branches, Figure $2 \mathrm{~b}$. Considering the sample prepared with the graft copolymer synthesized for 3 hours without the coagent in comparison with the sample SAN/EPDM-3-T ( prepared with coagent TAC), different structure is observed, i.e. a higher concentration of side branches, Figure $1 \mathrm{~b}$, and a weakening of mechanical properties of the blends are obtained. The similar behavior is observed for the extended polymerization time (7 hours) of synthesis of graft copolymers, i .e. increase of concentration of side branches, which caused continued weakening in mechanical properties of the blends. For example, tensile strength for the sample
SAN/EPDM-3 (prepared with coagent TAC) was cca. $27 \mathrm{MPa}$ while for the sample SAN/EPDM-7 this value decreased to $22.5 \mathrm{MPa}$, Figure 4. From that it can be concluded that the concentration of side branches, i.e. graft density is responsible for interactions between the polymers in a blend. However, there are negligible differences in the mechanical properties of blends when these are prepared with compatibilizers synthesized for 7 hours (with and without TAC), Figures 1c, 2c. In this case, it is assumed that when the concentration of side branches is higher then optimal, then the effect of the different structures of the graft copolymers on miscibility would not be observed. Considering the sample composition 95/5/5 it can be seen that addition of compatibilizer improves compatibility but the effect of different structures of the graft copolymers on miscibility is negligible, which can be seen from the results of mechanical properties. This is explained with the low concentration of the dispersed EPDM phase.

\subsection{Morphology of the SAN/EPDM/EPDM-g-PS blends}

The morphology of SAN/EPDM blends compositions $95 / 5$ and $90 / 10$ can be seen on the micrographs of the cryogenically fractured surfaces of

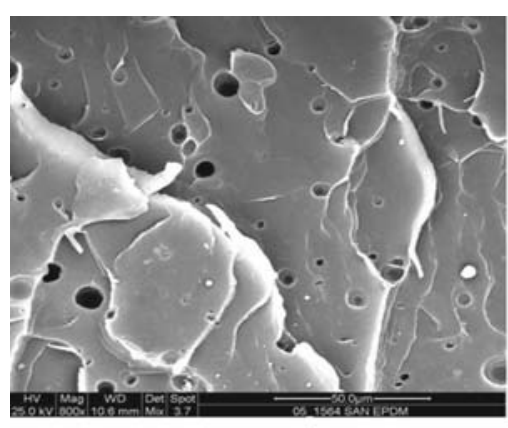

a) SAN/EPDM 95/5

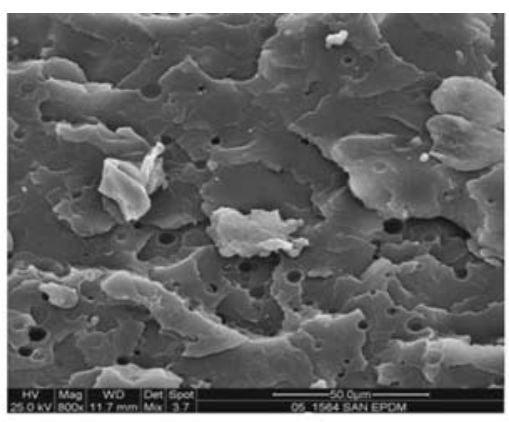

b) SAN/EPDM-3

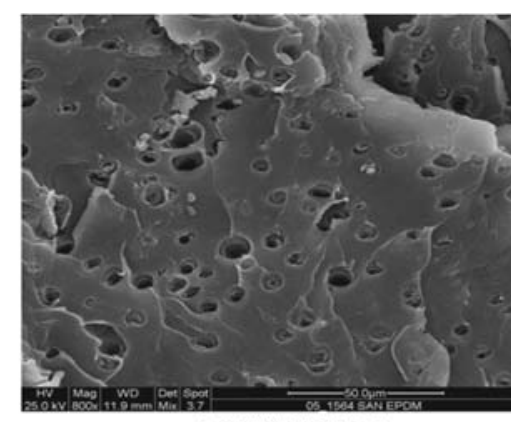

c) SAN/EPDM-3-T

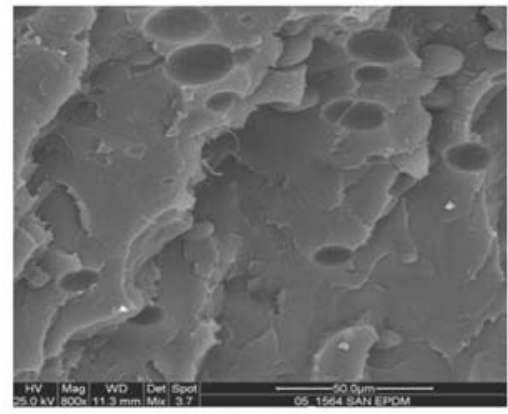

d) SAN/EPDM-7

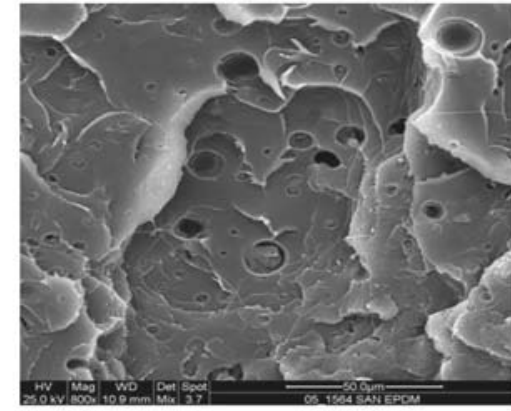

e) SAN/EPDM-7-T

Figure 6. SEM micrographs of SAN/EPDM/EPDM-g-PS blends (95/5/5): a) without a compatibilizer, b) formed by grafts synthesized for 3 hours, c) formed by grafts synthesized for 3 hours using TAC, d) formed by grafts synthesized for 7 hours, e) formed by grafts synthesized for 7 hours using TAC 


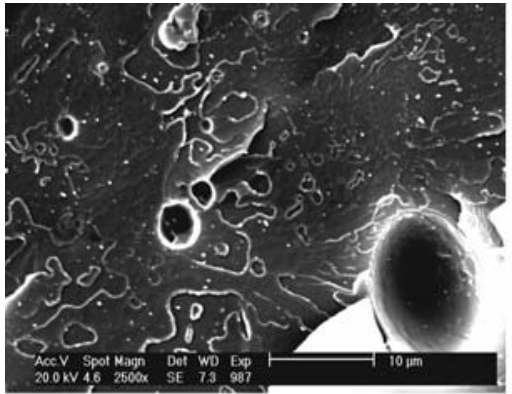

a) SAN/EPDM $90 / 10$

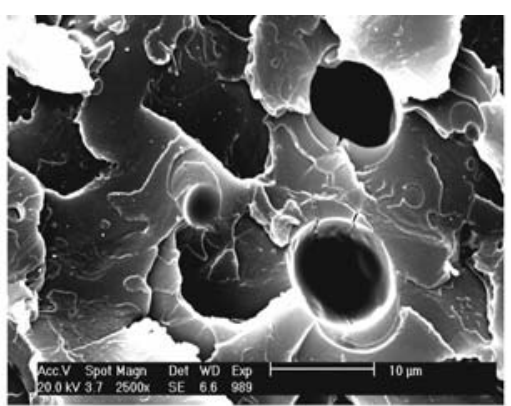

b) SAN/EPDM-3

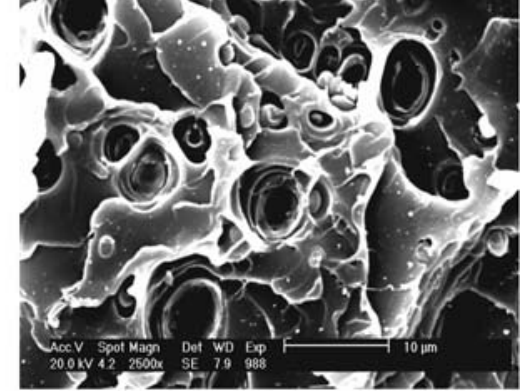

c) SAN/EPDM-3-T

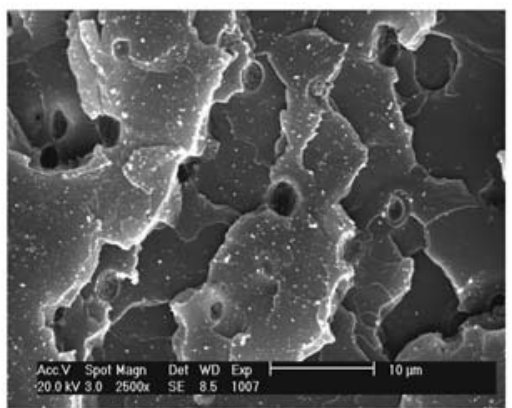

d) SAN/EPDM-7

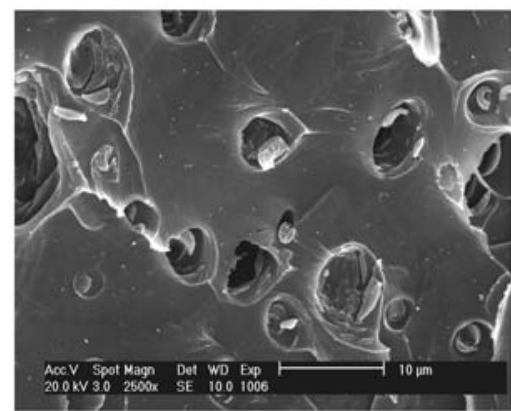

e) SAN/EPDM-7-T

Figure 7. SEM micrographs of SAN/EPDM/EPDM-g-PS blends (90/10/5): a) without a compatibilizer, b) formed by grafts synthesized for 3 hours, c) formed by grafts synthesized for 3 hours using TAC, d) formed by grafts synthesized for 7 hours, e) formed by grafts synthesized for 7 hours using TAC

SAN/EPDM blends, Figures 6 and 7. A different morphology of the studied blends is obtained, which is result of various structures of the added synthesized graft copolymers. The blends attain a more uniform distribution of EPDM polymer in the SAN matrix, which can be seen when comparing micrographs a)-e) on Figures 6 and 7. Considering the morphology of the samples SAN/EPDM-3 and SAN/EPDM-3-T, Figure $6 \mathrm{~b}$ and $6 \mathrm{c}$, (particle size of dispersed phase are $4.7 \mu \mathrm{m}$ and $2.9 \mu \mathrm{m}$, respectively), it can be seen some size reduction and homogeneity of the dispersed phase as well as for the samples prepared with the graft copolymers synthesized 7 hours with and without coagent TAC, Figure 6d and 6e (particle sizes of dispersed phase are $9.8 \mu \mathrm{m}$ and $5.9 \mu \mathrm{m}$, respectively). It is assumed that slight size reduction of the dispersed phase in the studied samples compositions 95/5/5 could be the result of the low concentration of EPDM. Minor differences in morphology of the studied blends are reflected in the negligible changes of mechanical properties.

Notable differences in the size and distribution of the dispersed phase for samples compositions 90/10/5 (prepared with graft copolymers synthesized with and without TAC) can be seen on micrographs $7 b$ and $7 c$. On micrograph $7 c$ the domains of the dispersed phase are smaller $(2.8 \mu \mathrm{m})$ and much better distributed in the matrix than the domains of the other studied blends (particle size are in the range of 3.1-6.4 $\mu \mathrm{m}$ ) micrograph $7 \mathrm{~b}, 7 \mathrm{~d}$ and $7 \mathrm{e}$. It is obvious that graft copolymers with a lower graft density of side branches, Figure $2 b$ form the finest morphology, which requires better interactions and improves compatibility in blends. It can be concluded that effect of different concentration of side branches on compatibility in blends is particularly visible when the concentration of side branches is lower or equal to the optimal (micrographs $6 \mathrm{c}$ and $7 \mathrm{c})$. On the other hand, when the concentration of the side branches is higher then optimal the minor changes in compatibility are present in spite of different structure of compatibilizer (micrographs $7 \mathrm{~d}$ and $7 \mathrm{e}$ ). The results of the studied blend samples show good relation between morphology and the changes of mechanical properties.

\section{Conclusions}

Various parameters like polymerization time and presence of coagent TAC provide synthesis of graft copolymers of different structures, i.e., various concentrations of side branches. From the results of mechanical properties and the morphology it can be seen that different structures of graft copolymers, which is used as a compatibilizer, influence the 
miscibility in SAN/EPDM blends. The highest improvements in miscibility are obtained for the blends prepared with the graft copolymer (EPDMg-PS-3T), which contain the optimal concentration of side branches, i.e., optimal graft density.

\section{References}

[1] Ji Y., Ma J. H., Liang B.: In situ polymerization and in situ compatibilization of polymer blends of poly (2,6dimethyl-1,4-phenylene oxide) and polyamide 6 . Materials Letters, 59, 1997-2000 (2005).

[2] Wildes G. S., Harada T., Keskkula H., Paul D. R., Janarthanan V., Padwa A. R.: Synthesis and characterization of an amine-functional SAN for the compatibilization of PC/ABS blends. Polymer, 40, 3069-3082 (1999).

[3] Martin P., Devaux J., Legras R., van Gurp M., van Duin M.: Competitive reactions during compatibilization of blends of polybutyleneterephthalate with epoxide-containing rubber. Polymer, 42, 2463-2478 (2001).

[4] Higgin J. S., Tambasco M., Lipson J. E. G.: Polymer blends; stretching what we can learn through the combination of experiment and theory. Progress in Polymer Science, 30, 832-843 (2005).

[5] Fekete E., Földes E., Pukánszky B.: Effect of molecular interactions on the miscibility and structure of polymer blends. European Polymer Journal, 41, 727736 (2005).

[6] Utracki L. A.: Polymer Alloys and Blends. Carl Hanser, New York, (1990).

[7] Fayt R., Jerome R., Teyssie P.: Molecular design of multicomponent polymer systems. XII. Direct observation of the location of a block copolymer in lowdensity polyethylene-polystyrene blends. Journal of Polymer Science Part C: Polymer Letters, 24, 25-28 (1986).

[8] Janata M., Masaŕ B., Toman L., Vlček P., Látalová P., Brus J., Holler P.: Synthesis of novel types of graft copolymers by a 'grafting-from' method using ring- opening polymerization of lactones and lactides. Reactive and Functional Polymers, 57, 137-146 (2003).

[9] Eklind H., Maurer F. H. J., Steeman P. A. M.: Micromechanical and microdielectric transitions in P(S-g-EO) modified PPO/PMMA blends. Polymer, 38, 1047-1055 (1997).

[10] Cartier H., Hu G. H.: A novel reactive extrusion process for compatibilizing immiscible polymer blends. Polymer, 42, 8807-8816 (2001).

[11] Mitra S., Ghanbari-Siahkali A., Kingshott P., Rehmeier H. K., Abildgaard H., Almdal K.: Chemical degradation of crosslinked ethylene-propylene-diene rubber in an acidic environment. Part II. Effect of peroxide crosslinking in the presence of a coagent. Polymer Degradation and Stability, 91, 81-93 (2006).

[12] Coran A. Y.: Vulcanization. in 'Encyclopedia of Polymer Science and Engineering' (eds.: Mark H. F., Bikales N. M., Overberger C. G., Menges G., Kroschwitz J. I.) Wiley Interscience Publication, New York, Vol 17, 666-698 (1985).

[13] Ptiček A., Hrnjak-Murgiæ Z., Jelenčić J., Kovačić T.: Study of the effect of structure of ethylene-propylenediene-graft-polystyrene copolymers on their physical properties. Polymer Degradation and Stability, 90, 319-325 (2005).

[14] Dikland H. G., Hulskotte R. J. M., Van der Does L., Bantjes A.: The mechanism of EPDM peroxide vulcanizations in the presence of triallylcyanurate as a coagent. Kautschuk und Gummi, Kunststoffe, 46, 608-613 (1993).

[15] Kumar M. S. C., Alagar M.: Development and characterisation of vinyloxyaminosilane grafted ethylenepropylene-diene terpolymer (EPDM-g-VOS) for engineering applications. European Polymer Journal, 38, 2023-2031 (2002).

[16] Mathew M., Thomas S.: Compatibilisation of heterogeneous acrylonitrile-butadiene rubber/polystyrene blends by the addition of styrene-acrylonitrile copolymer: effect on morphology and mechanical properties, Polymer, 44, 1295-1307 (2003). 